ORIGINAL ARTICLE

\title{
HIGH PREVALENCE OF Blastocystis spp. INFECTION IN CHILDREN AND STAFF MEMBERS ATTENDING PUBLIC URBAN SCHOOLS IN SÃO PAULO STATE, BRAZIL
}

\author{
Mayra Frozoni REBOLLA(1), Eliete Maria SILVA(2), Jancarlo Ferreira GOMES(3), Alexandre Xavier FALCÃO(4),
} Maria Vicentina Frozoni REBOLLA(5) \& Regina Maura Bueno FRANCO(1)

\begin{abstract}
SUMMARY
After a gastroenteritis outbreak of unknown etiology in the municipality of Sebastião da Grama, São Paulo, Brazil, we conducted a parasitological survey to establish the epidemiological profile of enteroparasitosis in children and staff members attending the public urban schools in operation in town. The cross-sectional study evaluated 172 children aged 11 months to 6 years old and 33 staff members aged 19 to 58 years old. Overall, $96(55.81 \%)$ children and $20(60.61 \%)$ staff members were mono-parasitized, while 58 $(33.72 \%)$ children and $4(12.12 \%)$ workers were poly-parasitized. Protozoa $(88.37 \% ; 72.73 \%)$ was more prevalent than helminthes $(3.48 \% ; 0 \%)$ in children and staff members respectively. Blastocystis spp. was the most prevalent parasite in children (86.63\%) and staff members $(66.67 \%)$. The age of 1 year old or less was found to be associated with increased prevalence of giardiasis [OR = 13.04; 95\% CI 2.89-58.91; $p=0.00]$ and public garbage collection was identified as a protective factor against intestinal helminth infections $[\mathrm{OR}=0.06 ; 95 \%$ CI $0.00-0.79 ; p=0.03]$. Although most of the children tested positive for Blastocystis spp. and also presented clinical signs/symptoms $(62.2 \%)$, this association was not statistically significant [OR $=1.35 ; 95 \% \mathrm{CI} 0.53-3.44 ; p=0.51]$. Intestinal parasites still represent a public health concern and this study underscores the importance of further investigations to better understand the pathogenic role of Blastocystis spp.
\end{abstract}

KEYWORDS: Blastocystis spp.; Giardia duodenalis; Intestinal parasites; Day care centers; Children.

\section{INTRODUCTION}

Blastocystis is the most common enteric parasite present in humans, especially in children and adults in developing countries ${ }^{1,2}$. It is considered a zoonosis with fecal-oral route of transmission ${ }^{1,3,4}$. Blastocystis spp. has attracted interest for its high frequency, global distribution and association with a variety of gastrointestinal disorders ${ }^{1,5}$. Gastroenteritis is a major cause of morbidity in children aged zero to 3 years old worldwide ${ }^{6}$ and recently a significant association between Blastocystis spp. and diarrhea symptoms has been found in children ${ }^{5}$. In developed countries, epidemiologic studies of Blastocystis infection showed incidence rates as high as $50 \%$ in different populations ${ }^{5}$. Poverty, poor personal hygiene, lack of proper sanitation, and close animal contact have been considered as risk factors for Blastocystis spp. infection ${ }^{4,7,8}$. As highlighted by Pipalsatitpong et al. ${ }^{9}$, the epidemiology of blastocystosis in children who live in crowded settings such as day-care centers has been rarely explored when compared to other parasites. Currently, the high prevalence of blastocystosis in developing countries makes control of this parasite a challenge for public health authorities ${ }^{2}$. Thus, in the beginning of
July 2010, a gastroenteritis outbreak of unknown etiology occurred in a public urban daycare center of a municipality named São Sebastião da Grama (São Paulo, Brazil). After the notification of the first case, a parasitological survey was conducted to establish the epidemiological profile of enteroparasitosis in children and staff members attending the two public urban educational institutions in operation in the city: the daycare center where the outbreak occurred and a preschool.

\section{MATERIALS AND METHODS}

\section{Ethics statement}

This study was approved by the Ethics Committee of the School of Medical Sciences - Unicamp (reference no. 404/2010; CAAE: 1854.0.000.146-10). Additionally, the Municipal Departments of Health and Education of São Sebastião da Grama granted their permission to carry out the study. Health and education authorities, school directors, and teachers were informed about the aim and procedures of the study before the schools visitation. Parents/guardians of children and staff members of schools gave their written informed consent for the current study.

(1) University of Campinas (UNICAMP), Institute of Biology, Department of Animal Biology. Brazil. E-mails: mayrafrozonirebolla@gmail.com; mfranco@unicamp.br

(2) University of Campinas (UNICAMP), School of Nursing, Brazil. E-mail: emsilva@unicamp.br

(3) University of Campinas (UNICAMP), Institute of Biology, Brazil. E-mail: jgomes@ ic.unicamp.br

(4) University of Campinas (UNICAMP), Institute of Computing, Brazil. E-mail: afalcao@ic.unicamp.br

(5) Epidemiological surveillance nurse. São Sebastião da Grama, São Paulo, Brazil. E-mail: vicentinafrozoni@hotmail.com

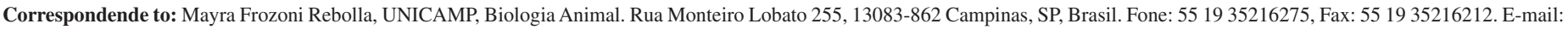
mayrafrozonirebolla@gmail.com 


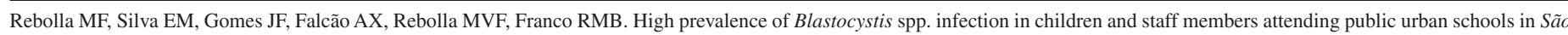
Paulo State, Brazil. Rev Inst Med Trop Sao Paulo. 2016;58:31.

Participation was voluntary, and hence, withdrawal was possible anytime without further obligation. Parasitological and questionnaire data were encoded and treated confidentially. All families and adults received the laboratory results of the exams, and those diagnosed positively received adequate medical treatment. Educational workshops were developed for the children, their families and caregivers for prevention of intestinal parasitic diseases.

\section{Study area and design}

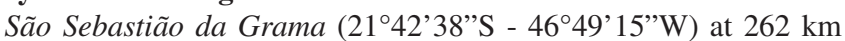
from São Paulo, Brazil, has a total population of 12.000 inhabitants. The municipality is located on the Mantiqueira Mountains at 945 meters above sea level. In this region, the climate is tropical altitude, with annual rainfall between $1,000-1,500 \mathrm{~mm}$. Mean temperatures range between $18^{\circ} \mathrm{C}$ and $20^{\circ} \mathrm{C}$. There are intense summer rains and frosts can occur in the winter. Services and agriculture are the main economical activities ${ }^{10}$. There were two schools in operation in the city urban area: a daycare center ( $21^{\circ} 42^{\prime} 47^{\prime \prime} \mathrm{S}-46^{\circ} 49^{\prime} 11^{\prime}$ 'W) attended by children from 4 months

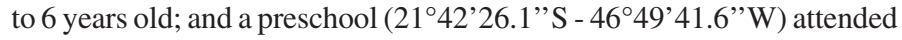
by children from 4 to 6 years old. The daycare center was the location of the gastroenteritis outbreak caused by an unknown etiological agent, whereas the preschool had no gastroenteritis cases reported. A cross sectional survey was carried out in these two schools during July to September 2010. Children and staff members attending school activities were invited to voluntarily take part in the study and those who accepted were subjected to parasitological examinations. A questionnaire about clinical and sociodemographic characteristics of children was also applied. Unique identification numbers were assigned to participants. Risk behaviors in the child's school environment were assessed by a pre-coded questionnaire using the participant observations.

\section{Fecal sample collection and laboratory testing}

Three fecal samples were collected from each participant on alternate days (maximum 10 days in total), using Three Fecal Test (TF-Test) collector tubes with $7 \%$ buffered formalin. The qualitative diagnosis of helminth eggs and larvae and protozoa cysts was obtained after processing fecal samples using two methods of concentration: $T F$ Test Conventional ${ }^{11}$ (sedimentation technique) and TF-Test Modified (sedimentation and flotation techniques) and Lugol's iodine staining method. The use of TF-Test Conventional and Modified techniques for the stool processing is justified by their sensitive and specific parasitological diagnostic capacity ${ }^{12,13,14}$ their great usability and their inexpensiveness for large parasitological surveys ${ }^{11}$. The TF-Test technique is also reported in the National plan of surveillance and control of intestinal parasites of the Brazilian Ministry of Health ${ }^{15}$. Infection by Blastocystis was detected by the presence of vacuolar, cyst, trophozoite or other forms in the stool specimens. Tests for viral and bacterial agents were not performed.

\section{TF-Test conventional}

Approximately $6 \mathrm{~mL}$ of stool and liquid preservative were used per sample. In this suspension, we added one drop of mild colorless detergent and $3 \mathrm{~mL}$ of ethyl acetate $99.5 \%$, and they were homogenized vigorously. The collector tubes were attached to another piece of TF-Test, named filter set, and centrifuged (500 x $g$, 2 min). Right after, the supernatant was decanted. For the remaining pellet, 10 drops of physiological $\mathrm{NaCl}$ solution were added and homogenized. A microscope slide was prepared with 1 or 2 drops of fecal material and 1 drop of Lugol's iodine (2.0\% solution), and examined under a microscope ${ }^{11}$.

\section{TF-Test modified}

The fecal sediment obtained $(600 \mu \mathrm{l})$ through the TF-Test Conventional technique was divided in two tubes: $300 \mu \mathrm{l}$ were transferred to one TF-Test collector tube for the flotation step, and the remaining $300 \mu \mathrm{L}$ to another collector tube for the sedimentation step. In the collector tube used for the flotation step, we added $3 \mathrm{~mL}$ of zinc sulphate solution $(1.18 \mathrm{~g} / \mathrm{mL})$, and the entire suspension was homogenized. After that, the tube was completed with the same solution until the formation of a positive meniscus-at the edge of the collector tube. A microscope slide was put on top of the tube for 15 minutes. After this period, the slide was removed, and one drop of Lugol's iodine ( $2.0 \%$ solution) was placed on the fecal smear for examination under a microscope. In the collector tube used for the sedimentation step, we added 3 drops of a liquid compound (sodium hypochlorite + sodium hydroxide + sodium chloride + water, with active chlorine content), and the entire suspension was homogenized and allowed to stand for five minutes. After this, we added $3 \mathrm{~mL}$ of ethyl acetate $99.5 \%$, and the material was shaken vigorously for 30 seconds, and then centrifuged (500 x $g, 1 \mathrm{~min})$. The supernatant was decanted, leaving $0.5 \mathrm{~mL}$ of fecal suspension in the tube. Finally, one or two drops of fecal material were placed in the microscope slide with a drop of Lugol's iodine (2.0\% solution), and a smear was prepared and examined under a microscope.

\section{Questionnaire about clinical and sociodemographic characteristics of the children}

Based on prior experience and on a review of the literature on intestinal parasitic infections $s^{4,6,8,15,16}$, we developed a standard questionnaire for children in order to determine their sociodemographic and clinical characteristics and to later assess the correlation between the questionnaire's answers and potential infection risk factors. The instrument contained questions regarding sex, age, the mother's educational level, type of housing, water supply, drinking water, sewage system, garbage disposal, monthly household income, use of footwear, pork meat consumption, origin of the vegetables consumed during the meals, and the presence of other children or domestic animals in the house. The questionnaire also asked about clinical signs/symptoms such as abdominal pain, anorexia, vomiting, flatulence, nausea, and elimination of parasites visible to the naked eye, loss of appetite, constipation, fever, headache, diarrhea and anal itching.

\section{Questionnaire about the child's school environment}

For evaluation of the hygienic behavior of the children and their parents, and of staff members, and disposable infrastructure, data was collected with a pre-coded questionnaire using participant observations in the schools. This instrument was produced according to statistically significant risk factors present in the literature about infectious diseases in daycare centers, nurseries, preschools ${ }^{17,18,19}$. The participant observation is not a simple observation; indeed, it is a systematic technique ${ }^{20}$. The observation for a long period can reduce the observer reactivity degree when people get used to the presence of the observer ${ }^{21}$. The observation included frequent visits to the daycare center and to the preschool. The variables studied fell broadly into three categories: (I) Infrastructure and material, (II) Children group training and (III) Routines/personal care (Table 1).

\section{Statistical analysis}

Prevalence was defined as the number of existing cases (old and new) occurring during the observation period. The chi-square test was used 


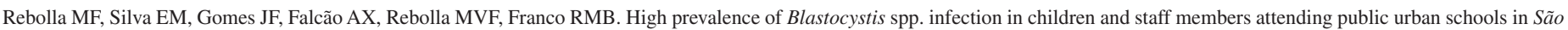
Paulo State, Brazil. Rev Inst Med Trop Sao Paulo. 2016;58:31.

in order to compare proportions. A multiple regression logistic model using the statistical software Stata (version MP11) was performed for multivariate analysis to assess the independent association between risk factors and outcome variables (positivity for enteroparasites and commensals, intestinal helminthes, intestinal protozoan, Blastocystis spp. and $G$. duodenalis). The $95 \%$ confidence intervals and a $p \leq 0.05$ were assumed as statistical significant.

\section{RESULTS}

\section{Study participation}

Overall, 238 children and 44 staff members attending school were invited to participate, the majority of children $(n=191 ; 80.25 \%)$ had written informed consents from their parents/guardians and had completed the parasitological data. The written informed consent was obtained for a large number of staff members $(n=34 ; 77.27 \%)$. Children who delivered less than three fecal samples were not included in the analysis $(n=19$; $7.98 \%)$, as well as staff members $(n=1 ; 2.27 \%)$. Hence, $172(72.26 \%)$ children and $33(75.0 \%)$ staff members had complete datasets.

\section{Clinical and sociodemographic characteristics}

We analyzed feces from 172 children aged 11 months to 6 years old, with a mean age of $4.55(\mathrm{SD}=1.32)$ years, and 33 staff members aged 19 to 58 years, with a mean age of $39.98(\mathrm{SD}=9.65)$. Among the children, $92(53.49 \%)$ were girls, $108(62.8 \%)$ attended the preschool and 64 $(37.2 \%)$ attended the daycare center. In addition, 161 (63.6\%) children lived in brick houses; 130 (75.58\%) had access to public water supply; and $106(61.63 \%)$ had access to drinking water. Also, the households of $152(88.37 \%)$ children had sewage systems, and public garbage collection was available for $168(97.68 \%)$ children. Among the staff members, $32(96.96 \%)$ were women, $23(69.7 \%)$ worked at the preschool and 10 $(30.3 \%)$ worked at the daycare center. A hundred and nineteen mothers $(69.19 \%)$ had 6-11 years of study, and $72(41.86 \%)$ children had a low family income of BRL 501-1000. There were other children in the same house for 92 (53.49\%) children, and 109 (63.4\%) had domestic animals nearby the house. The origin of vegetables was household garden/market for $104(60.46 \%)$ children, and $133(77.32 \%)$ consumed pork meat. A hundred and forty-three children $(83.14 \%)$ reported wearing footwear routinely and $122(70.9 \%)$ children presented clinical signs/symptoms.

\section{Child's school environment}

In Table 1 it is possible to observe a list of various potential determinants for an increased risk of diarrheal diseases and parasitosis, with special consideration of the hygienic behavior, drinking water and sanitation facilities.

Regarding the category "infrastructure and material", there was no individual personal hygiene products (bath sponges were shared, for example) and packages with protection mechanism. Furthermore, there was no proper drinking water available for children in the establishments studied: tap filters were not available and mugs were shared. In relation to the category "children group training", in the daycare center, if there was a shortage of staff in the daycare center, children were all grouped together in one classroom. Concerning the "routines/personal care", the nursery meals occurred inside the classrooms, and these environments were not cleaned afterwards. It was observed that staff members who changed diapers also prepared or served food when another staff member was absent. Staff members rarely followed good practices such as washing children's hands or their own at key moments, as well as for changing diapers. Sometimes staff members suffering from diarrhea were not reallocated to other tasks that presented lower risks of spreading infection. Occasionally, floor and table surfaces were not cleaned on a daily basis. Oftentimes, parents did not get in contact with the school in case their children developed diarrhea, and these children continued attending school before the school staff eventually notice this symptom. Cleaning routines were not intensified in diarrhea cases and, finally, the local health department was not warned about children with diarrhea in the child-care facility.

\section{Prevalence of enteroparasites and commensals}

The overall prevalence of enteroparasites and commensals was high among children $(89.53 \%$ CI $95 \%=84.07-93.28)$ and staff members $(72.73 \%$ CI $95 \%=55.78-84.93)$ in both daycare center and preschool. As estimated, in the daycare center the prevalence of enteroparasites and commensals was superior among children $(98.44 \%$, CI 95\% $=91.67-$ $99.72)$ and staff members $(80.0 \%$, CI $95 \%=49.02-94.33)$ when compared to the preschool, respectively in children $(84.26 \%$, CI $95 \%=76.23-$ $89.93)$ and adults $(69.57 \%$, CI $95 \%=49.13-84.40)$.

In the present study, protozoa $(88.37 \%)$ were more prevalent than helminthes $(3.48 \%)$ in children. Blastocystis spp. (86.63\%) was the most prevalent protozoa and Taenia spp. (1.16\%) and Trichuris trichiura $(1.16 \%)$ were the most prevalent helminthes. It is important to note that there was a high concentration of cases of giardiasis in nursery $(\mathrm{N}=12$; $60.0 \%$ data not shown). In general, there were more children monoparasitized $(55.81 \%)$ than poly-parasitized (33.72\%). Nevertheless, in the gastroenteritis outbreak, the proportion of poly-parasitized children (45.31\%) was very close to the mono-parasitized one (53.12\%), although the proportion of children harboring only one intestinal parasite had been slightly larger (Table 2).

It is important to note that from the 58 children harboring more than one type of intestinal parasite, $57(98.27 \%)$ were parasitized by Blastocystis spp. In preschool, every poly-parasitized child (100.0\%) had Blastocystis spp. and in daycare center this percentage was $96.55 \%$ (Table 3).

In general, $72.73 \%$ of the staff members were parasitized by protozoa. Helminthes were not identified. Blastocystis spp. (66.67\%) was the most prevalent parasite. Most of the staff members $(60.61 \%)$ were hosting only one intestinal parasite, and this proportion was similar between workers of the daycare center $(60.0 \%)$ and of the preschool (69.56\%) (Table 4).

Only four (12.12\%) adults in preschool were poly-parasitized: Blastocystis spp. and E. nana (6.06\% CI 95\% = 1.68-19.61), Blastocystis spp. and E. coli $(3.03 \%$ CI $95 \%=0.54-15.32)$ and Blastocystis spp. and G. duodenalis $(3.03 \%$ CI $95 \%=0.54-15.32)$ and, as for children, the parasitism by Blastocystis spp. was high (100.0\% of the poly-parasitized workers).

\section{Statistical analysis}

In univariate analysis, several sociodemographic characteristics of children were significantly associated with intestinal parasitic infections.

Among the risk factors examined, the age of 1 year or less was found to be associated with an increased prevalence of giardiasis $[\mathrm{OR}=33.11$; 
Rebolla MF, Silva EM, Gomes JF, Falcão AX, Rebolla MVF, Franco RMB. High prevalence of Blastocystis spp. infection in children and staff members attending public urban schools in São Paulo State, Brazil. Rev Inst Med Trop Sao Paulo. 2016;58:31.

Table 1

Protection factors against enteroparasitosis in children's school environment in São Sebastião da Grama, São Paulo State, Brazil, 2010

\begin{tabular}{|c|c|c|c|}
\hline Categories & Protection factors & Daycare center & Preschool \\
\hline \multirow[t]{2}{*}{ (I) Infrastructure and material } & $\begin{array}{l}1 \text { - Individual personal hygiene products and packages with protection } \\
\text { mechanism }\end{array}$ & 0 & 0 \\
\hline & 2 - Potable drinking water (boiled, filtered or chlorinated) & 0 & 0 \\
\hline \multirow[t]{2}{*}{ (II) Children group training } & $\begin{array}{l}3 \text { - Children cannot be grouped together in one classroom if there is shortage } \\
\text { of staff }\end{array}$ & 1 & 2 \\
\hline & 4-Children separated into groups by age & 2 & 2 \\
\hline \multirow{15}{*}{ (III) Routines/personal care } & $\begin{array}{l}5 \text { - Dining hall used only for meals. If the nursery meals occur inside the } \\
\text { classrooms, these environments are clean afterwards }\end{array}$ & 0 & 2 \\
\hline & $\begin{array}{l}6 \text { - Cloth diaper is washed and decontaminated outside the school } \\
\text { environment }\end{array}$ & NO & NO \\
\hline & $\begin{array}{l}7 \text { - Ensure that children wear clothing over their diapers to reduce leakage } \\
\text { from diapers }\end{array}$ & 2 & 2 \\
\hline & 8 -Staff members who change diapers should not prepare or serve meals & 1 & 2 \\
\hline & 9 - Reinforce good hand washing technique* & 0 & 0 \\
\hline & $\begin{array}{l}10-\text { Reinforce good hand washing technique for all the adults at key } \\
\text { moments** }\end{array}$ & 1 & 1 \\
\hline & $\begin{array}{l}11 \text { - Reinforce good hand washing technique for all the children at key } \\
\text { moments** }\end{array}$ & 1 & 1 \\
\hline & $12-$ Reinforce good diapering practices $* * *$ & 0 & 2 \\
\hline & $\begin{array}{l}13 \text { - Transfer adults with diarrhea to tasks that minimize the opportunities } \\
\text { for spreading infection (for example, administrative work instead of meals } \\
\text { preparation) }\end{array}$ & 1 & 1 \\
\hline & $14-$ Clean surfaces daily & 2 & 1 \\
\hline & $15-$ Clean toys frequently & $\mathrm{NO}$ & NO \\
\hline & 16 - Parents should contact school if their child develops diarrhea & 1 & 1 \\
\hline & $\begin{array}{l}17 \text { - Exclude any child with diarrhea from the children-care setting until } \\
\text { the diarrhea has stopped }\end{array}$ & 0 & 0 \\
\hline & $\begin{array}{l}18 \text { - Notify the local health department about any child's diarrhea in the } \\
\text { child-care facility }\end{array}$ & 0 & 0 \\
\hline & 19 - Cleaning routines must be intensified in diarrhea cases & 0 & NO \\
\hline TOTAL & & 12 & 17 \\
\hline
\end{tabular}

$\mathrm{NO}=$ not observed; $0=$ No; $1=$ Yes; $2=$ Yes/Not applicable. $*$ Wet hands with running water and apply soap. Rub hands together and scrub all surfaces, including the area under the fingernails. Rinse hands well under running water. Dry hands using a disposable paper towel, if possible, and use it to turn off the faucet. ** Before handling, preparing, serving or eating, after using the bathroom, changing diapers, after handling garbage, playing in the sand Park with animals or toys, and before and after taking care of someone who is sick. *** Separate diaper-changing areas from children's recreational area and meal preparation areas. Use disposable gloves and change them after each diaper change. Use disposable paper over diaper-changing surfaces and change it after each diaper change. Both, the staff member and the child should wash hands after each diaper change.

95\% CI - 7.76-141.36; $p=0.00]$. Children that consumed water from public supplies had a higher risk of been infected by enteroparasites and/or commensals $[\mathrm{OR}=2.82 ; 95 \% \mathrm{CI}-1.03-7.71 ; p=0.04]$ and by intestinal protozoa $[\mathrm{OR}=2.95 ; 95 \% \mathrm{CI}-1.12-7.71 ; p=0.02]$. Public sewage systems were also significantly associated with positive fecal examination for enteroparasites and/or commensals [OR $=3.56 ; 95 \%$ CI - 1.11-11.37; $p=0.03$ ], for intestinal protozoa [OR $=4.22 ; 95 \%$ CI - 1.40-12.73; $p=0.01]$, and for Blastocystis spp. [OR $=3.40 ; 95 \%$ CI - 1.15-10.03; $p=0.02$ ]. Children with available public garbage collection had a higher probability of being infected by intestinal protozoa $[\mathrm{OR}=16.6 ; 95 \% \mathrm{CI}-1.43-193.08 ; p=0.02]$ and Blastocystis spp. [OR $=14 ; 95 \% \mathrm{CI}-1.21-161.20 ; p=0.03]$.
Most children were parasitized by Blastocystis spp. and presented clinical signs (62.2\%), 65 (37.79\%) of them being mono-parasitized by Blastocystis spp. and $42(24.41 \%)$ poly-parasitized by Blastocystis spp. In spite of that, the association between infection by Blastocystis spp. and the presence of clinical signs is not statistically significant $[\mathrm{OR}=1.35$; 95\% CI - 0.53-3.44; $p=0.51]$. On the other hand, $42(24.41 \%)$ children were parasitized by Blastocystis spp., but did not have any symptoms.

The age between 4 and 5 years old was found to be a protective factor against parasitic protozoal infection $[\mathrm{OR}=0.34 ; 95 \% \mathrm{CI}-0.12-0.90$; $p=0.03]$, Blastocystis spp. infection [OR $=0.33 ; 95 \% \mathrm{CI}-0.13-0.82$; $p=0.01]$, and $G$. duodenalis infection $[\mathrm{OR}=0.13 ; 95 \% \mathrm{CI}-0.02-0.58$; 


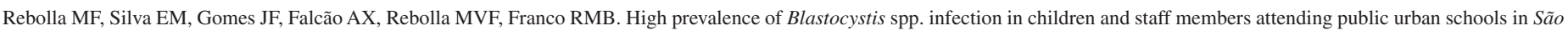
Paulo State, Brazil. Rev Inst Med Trop Sao Paulo. 2016;58:31.

Table 2

Prevalence of enteroparasites and commensals according to species in children attending public urban schools in São Sebastião da Grama, São Paulo State, Brazil, 2010

\begin{tabular}{|c|c|c|c|c|c|}
\hline \multirow{3}{*}{ Category } & \multirow{3}{*}{$\begin{array}{c}\text { Daycare center }(\mathrm{n}=64) \\
\text { infected }(\%)\end{array}$} & \multirow{3}{*}{$\begin{array}{c}\text { Preschool }(\mathrm{n}=108) \\
\text { infected }(\%)\end{array}$} & \multicolumn{3}{|c|}{ TOTAL $(\mathrm{N}=172)$} \\
\hline & & & \multirow{2}{*}{ infected $(\%)$} & \multicolumn{2}{|c|}{$95 \% \mathrm{CI}$} \\
\hline & & & & Lower & Upper \\
\hline Protozoa & $63(98.44)$ & $89(82.4)$ & $152(88.37)$ & 82.72 & 92.35 \\
\hline Blastocystis spp. & $62(96.87)$ & $87(80.55)$ & $149(86.63)$ & 81.54 & 91.71 \\
\hline Endolimax nana ${ }^{+}$ & $7(10.93)$ & $23(21.29)$ & $30(17.44)$ & 11.77 & 23.11 \\
\hline Giardia duodenalis & $17(26.56)$ & $3(2.77)$ & $20(11.63)$ & 6.84 & 16.42 \\
\hline Entamoeba coli ${ }^{+}$ & $8(12.5)$ & $11(10.18)$ & $19(11.05)$ & 6.36 & 15.73 \\
\hline Entamoeba histolytica/E. dispar ** & $3(4.68)$ & -- & $3(1.74)$ & - & 3.70 \\
\hline Iodamoeba bütschllii ${ }^{+}$ & $1(1.56)$ & $1(0.92)$ & $2(1.16)$ & - & 2.76 \\
\hline Helminthes & $1(1.56)$ & $5(4.62)$ & $6(3.48)$ & 1.61 & 7.40 \\
\hline Taenia spp. & - & $2(1.85)$ & $2(1.16)$ & - & 2.76 \\
\hline Trichuris trichiura & & $2(1.85)$ & $2(1.16)$ & - & 2.76 \\
\hline Hookworms & - & $1(0.92)$ & $1(0.58)$ & - & 1.72 \\
\hline Strongyloides stercoralis & $1(1.56)$ & - & $1(0.58)$ & - & 1.72 \\
\hline Total & $63(98.44)$ & $91(84.26)$ & $154(89.53)$ & 84.07 & 93.28 \\
\hline Monoparasitized & $34(53.12)$ & $62(57.4)$ & $96(55.81)$ & 48.35 & $63.03-$ \\
\hline Poliparasitized & $29(45.31)$ & $29(26.85)$ & $58(33.72)$ & 27.08 & $41.07-$ \\
\hline
\end{tabular}

${ }^{+}$Commensals; ** Suggestive because diagnosis was not performed with ferric hematoxylin

Table 3

Multiple infections by enteroparasites in children attending public urban schools in São Sebastião da Grama, São Paulo State, Brazil, 2010

\begin{tabular}{|c|c|c|c|c|c|}
\hline \multirow{3}{*}{ Associations observed } & \multirow{3}{*}{$\begin{array}{c}\text { Daycare center }(n=64) \\
\text { infected }(\%)\end{array}$} & \multirow{3}{*}{$\begin{array}{c}\text { Preschool }(\mathrm{n}=108) \\
\text { infected }(\%)\end{array}$} & \multicolumn{3}{|c|}{ TOTAL (N=172) } \\
\hline & & & \multirow{2}{*}{ infected $(\%)$} & \multicolumn{2}{|c|}{$95 \% \mathrm{CI}$} \\
\hline & & & & Lower & Upper \\
\hline Blastocystis spp. and $G$. duodenalis & $16(25.0)$ & $1(0.93)$ & $17(9.88)$ & 6.26 & 15.26 \\
\hline Blastocystis spp. and E. nana & $3(4.69)$ & $14(12.96)$ & $17(9.88)$ & 6.26 & 15.26 \\
\hline Blastocystis spp., E. coli and $E$. nana & $3(4.69)$ & $5(4.63)$ & $8(4.65)$ & 2.38 & 8.91 \\
\hline Blastocystis spp. and $E$. coli & $4(6.25)$ & $3(2.78)$ & $7(4.07)$ & 1.99 & 8.16 \\
\hline Blastocystis spp. and E. histolytica/E. dispar* & $2(3.12)$ & - & $2(1.16)$ & 0.32 & 4.14 \\
\hline Blastocystis spp. and Hookworms & - & $1(0.93)$ & $1(0.58)$ & 0.10 & 3.22 \\
\hline Blastocystis spp., E. coli, E. nana and G. duodenalis & - & $1(0.93)$ & $1(0.58)$ & 0.10 & 3.22 \\
\hline Blastocystis spp., E. coli, and G.duodenalis & - & $1(0.93)$ & $1(0.58)$ & 0.10 & 3.22 \\
\hline Blastocystis spp., E. nana, and I. bütschllii & - & $1(0.93)$ & $1(0.58)$ & 0.10 & 3.22 \\
\hline Blastocystis spp., E. nana and Taenia spp. & - & $1(0.93)$ & $1(0.58)$ & 0.10 & 3.22 \\
\hline Blastocystis spp. and T. trichiura & - & $1(0.93)$ & $1(0.58)$ & 0.10 & 3.22 \\
\hline $\begin{array}{l}\text { E. coli, E. histolytica/E. dispar, E. nana, } \\
\text { G. duodenalis, I. bütschllii and S. stercoralis } \\
\end{array}$ & $1(1.56)$ & - & $1(0.58)$ & 0.10 & 3.22 \\
\hline TOTAL & $29(45.31)$ & $29(26.85)$ & $58(33.72)$ & 27.08 & 41.07 \\
\hline
\end{tabular}


Rebolla MF, Silva EM, Gomes JF, Falcão AX, Rebolla MVF, Franco RMB. High prevalence of Blastocystis spp. infection in children and staff members attending public urban schools in São Paulo State, Brazil. Rev Inst Med Trop Sao Paulo. 2016;58:31.

Table 4

Prevalence of enteroparasites and commensals according to species in staff members of public urban schools in São Sebastião da Grama, São Paulo State, Brazil, 2010

\begin{tabular}{|c|c|c|c|c|c|}
\hline \multirow{3}{*}{ Category } & \multirow{3}{*}{$\begin{array}{c}\text { Daycare center }(\mathrm{n}=10) \\
\text { infected }(\%)\end{array}$} & \multirow{3}{*}{$\begin{array}{c}\text { Preschool }(\mathrm{n}=23) \\
\text { infected }(\%)\end{array}$} & \multicolumn{3}{|c|}{ TOTAL N=33 } \\
\hline & & & \multirow{2}{*}{ infected $(\%)$} & \multicolumn{2}{|l|}{$95 \%$ CI } \\
\hline & & & & Lower & Upper \\
\hline Protozoa & $8(80.0)$ & $16(69.56)$ & $24(72.73)$ & 55.78 & 84.93 \\
\hline Blastocystis spp. & $6(60.0)$ & $16(69.56)$ & $22(66.67)$ & 49.61 & 80.25 \\
\hline Endolimax nana ${ }^{+}$ & $1(10.0)$ & $2(8.69)$ & $-3(9.09)$ & 3.14 & 23.57 \\
\hline Giardia duodenalis & - & $1(4.34)$ & $-1(3.03)$ & 5.40 & 15.32 \\
\hline Entamoeba coli $^{+}$ & $1(10.0)$ & $1(4.34)$ & $-2(6.06)$ & 1.68 & 19.61 \\
\hline Total & $8(80.0)$ & $16(69.57)$ & $24(72.73)$ & 55.78 & 84.93 \\
\hline Monoparasitized & $8(80.0)$ & $12(52.17)$ & $20(60.61)$ & 43.68 & 75.32 \\
\hline Poliparasitized & - & $4(17.39)$ & $4(12.12)$ & 4.82 & 27.33 \\
\hline
\end{tabular}

${ }^{+}$Commensals

$p=0.00]$. Children that consumed homegrown or market vegetables had a lower risk of been infected by intestinal protozoa $[\mathrm{OR}=0.97 ; 95 \%$ CI - 0.96-0.99; $p=0.01]$ and Blastocystis spp. [OR $=0.98 ; 95 \% \mathrm{CI}-$ $0.96-0.99 ; p=0.02]$. Residential garbage collection has also appeared as a protective factor against helminthic infections $[\mathrm{OR}=0.07 ; 95 \%$ CI - 0.00-0.69; $p=0.00]$.

Variables that were significant $(p<0.05)$ in the univariate analysis were reanalyzed to identify their independent effects in relation to outcomes variables. When multivariate analysis was performed, children $\leq 1$ year old remained as a risk factor for giardiasis [OR $=13.04 ; 95 \%$ CI - 2.89-58.91; $p=0.00]$. It is important to note that children at the age of 1 year or less were the most infected by $G$. duodenalis $(\mathrm{N}=8 ; 40.0 \%)$. Another aspect to be highlighted is that the number of children with $G$. duodenalis is inversely proportional to the age. Public garbage collection remains a protective factor against intestinal helminthic infections $[\mathrm{OR}=0.06 ; 95 \% \mathrm{CI}-0.00-0.79 ; p=0.03]$. Most children $(94.76 \%$ ) having access to waste collection were not parasitized by helminthes.

\section{DISCUSSION}

The high prevalence of Blastocystis spp. in children (86.63\%) and staff members $(66.67 \%)$ represents a public health problem in the studied urban settings. A few years ago, Blastocystis had already been reported in daycare centers in Brazil, where around $32.0 \%$ of children and $60.0 \%$ of adults were parasitized ${ }^{22}$. The high prevalence we found is similar to those reported by other recent studies in developing countries. In Morocco, Blastocystis hominis (64\%) was the most prevalent parasite in four schools located in both urban and rural areas of Tetouan ${ }^{23}$, and in Colombia the prevalence was $57.5 \%$.

Miller \& Minshew suggested that some concentration techniques were unsuitable to detect Blastocystis from fecal samples because the parasite could be easily disrupted ${ }^{24}$. Also, the sensitivity of microscopy examination of stool samples may be lower due to the variable polymorphic nature of Blastocystis ${ }^{25}$. However, recent studies that have also used TF-Test reported that these parasitological techniques provide a reliable estimate in humans ${ }^{12,14}$ especially for protozoan infections ${ }^{14}$, and also in animals ${ }^{26,27}$. These findings corroborate our results. The TFTest may have allowed the detection of a high prevalence of Blastocystis spp. because it preserves the specimens in the liquid based on buffered formalin, to present triple collection of fecal material, and because the method has a parasitic concentration principle that does not use tap water during the laboratory processing ${ }^{28}$.

Most of the children tested positive for Blastocystis spp. and presented clinical signs/symptoms (62.2\%), however, the association between symptomatic infection and the presence of Blastocystis spp. was not statistically significant. In contrast, another research showed a significant association between Blastocystis spp. and diarrhea symptoms in children under the age of five ${ }^{5}$. Despite this, a recent study has reasserted that we should consider it a pathogen when it is associated with symptoms and there are no other infectious agents ${ }^{29}$.

We did not implement molecular techniques, which are necessary in order to identify specific hosts with pathogenic potential. Molecular techniques have been useful in showing a high carriage of intestinal parasites in asymptomatic individuals from two poor Brazilian villages, revealing a large genetic variability of Blastocystis spp. ${ }^{30}$. Nevertheless, as already described by Guimarães \& Sogayar ${ }^{22}$, despite of the uncertain pathogenic role of Blastocystis spp., it is important that the clinical laboratories do not underestimate this diagnosis, because a significant frequency of infection has been found in different populations and among individuals with or without gastrointestinal complaints.

According to the univariate analysis, children that consumed public untreated water had a higher risk of being infected by intestinal protozoa. However, this association was not significant according to the multivariate analysis, even though a considerable number of epidemiologic studies have suggested the waterborne transmission of blastocystosis. Leelayoova et $a l .{ }^{4}$ indicated that contaminated rainwater might be a source of Blastocystis infection. 
The univariate analysis has also shown that children who consumed homegrown or market vegetables had a lower risk of being infected by intestinal protozoa and Blastocystis spp. Nevertheless, when the logistic model was applied, this association did not remain. In fact, David et al..$^{30}$ suggested that, given the large genetic heterogeneity observed among samples of Blastocystis, there may be multiple sources of infection other than water, such as person-to-person contact and contaminated food.

Public sewage systems were significantly associated with positive fecal tests for Blastocystis spp., although the latter association did not remain significant when multivariate analysis was performed. Notwithstanding, the results of a study in Malaysia showed that the presence of viable cysts in treated samples can be an indicator of the inefficiency of the treatment processes ${ }^{31}$ that are responsible for preventing Blastocystis from entering the environment. These data show that water can still carry on infectious parasite forms if water treatment is not properly applied. Waterborne outbreaks of protozoan parasites are far more common than outbreaks of helminthes, due to the smaller size of the transmissible forms of protozoa ${ }^{32}$. Waterborne transmission could play an important role in Blastocystis spp. infection, whose pathogenicity remains under debate ${ }^{3}$.

According to the univariate analysis, the age between 4 and 5 years old was found to be a protective factor against protozoal infections, such as Blastocystis spp. and G. duodenalis infections. However, this association was not significant in the multivariate analysis. Actually, Pipatsatitpong et al. ${ }^{9}$ and Mbae et al. ${ }^{33}$ showed the inverse situation: children who were 2 to 5 years old had a higher risk of Blastocystis infection than those who were less than 2 years ${ }^{9}$, and G. duodenalis and other protozoan infections increased significantly with age with the most affected age group being the one of 3-4 years old ${ }^{33}$.

In our study, we observed in the schools some risk factors of enteroparasitosis that had already been reported in the literature. Qualitative data obtained using appropriate methodology allowed a reliable and valid interpretation of the scenario observed in the schools. Besides, the close association between hygienic behavior and lower diarrhea morbidity reinforces the validity of the observed data ${ }^{34}$. Inappropriate sanitaryhygienic conditions facilitate the universal carriage of Blastocystis spp. and its easy transmission ${ }^{35}$. Santos et al. ${ }^{36}$ had previously reported the association of parasitic infections in children under similar conditions. Therefore, maintaining clean sanitary facilities and keeping good hygienic practices is important in order to avoid transmission of Blastocystis to others ${ }^{37}$. The child daycare center is a risk environment when appropriate sanitary hygienic measures are not adopted ${ }^{38}$.

The presence of non-adherent hygienic practices in changing diapers could favor the concentration of giardiasis cases in nursery and the high chance of finding children under the age of one year old or younger parasitized by G. duodenalis. In fact, some studies have shown that cysts are commonly present under diaper changers' fingernails and in fecal droplets found in diaper changing areas ${ }^{39,40}$, leading to a significant risk of giardiasis among children in diapers ${ }^{41}$.

Another important point is that public garbage collection appeared as a protective factor against intestinal helminthic infections, whose presence can be reduced in places with adequate health infrastructure under favorable environmental conditions ${ }^{42}$.
Our study highlights the importance of conducting periodical parasitological surveys, as has also been reported by Cañete et al. ${ }^{43}$. The results allowed the identification of positive cases, the offering of proper treatment and the installation of appropriate control and prevention measures in a timely manner. According to the results of the present study, the "Giardiasis control program in daycare centers and preschools"19 was implemented in the studied facilities in order to minimize the high prevalence of enteroparasites and to continue the efforts to implement control strategies and health education campaigns. As a result of these efforts, the local government provided water filters and other infrastructure facilities to the schools. Intestinal parasites still represent a public health concern and more studies are necessary to investigate the pathogenic role of Blastocystis spp.

\section{Study limitations}

Due to a particular situation of a gastroenteritis outbreak in one of the studied settings, the results are valid for this studied population. No bacterial or viral agents were tested and no molecular techniques were employed.

\section{ACKNOWLEDGMENTS}

The authors thank the managers, employees, healthcare professionals, families and all the children involved in the study of the city of São Sebastião da Grama, for the assistance provided by the laboratories of Protozoology and the Visual Computing in Biomedical and Health of the University of Campinas (UNICAMP), and for the financial support granted by the Conselho Nacional de Desenvolvimento Científico e Tecnológico $(\mathrm{CNPq})$. The authors have declared that no competing interests exist.

\section{REFERENCES}

1. Tan KS. New insights on classification, identification, and clinical relevance of Blastocystis spp. Clin Microbiol Rev. 2008;21:639-65.

2. El Safadi D, Gaayeb L, Meloni D, Cian A, Poirier P, Wawrzyniak I, et al. Children of Senegal river basin show the highest prevalence of Blastocystis sp. ever observed worldwide. BMC Infect Dis. 2014;14:164.

3. Anuar TS, Ghani MKA, Azreen SN, Salleh FM, Moktar N. Blastocystis infection in Malaysia: evidence of waterborne and human-to-human transmissions among the Proto-Malay, Negrito and Senoi tribes of Orang Asli. Parasit Vectors. 2013;6:40.

4. Leelayoova S, Siripattanapipong S, Thathaisong U, Naaglor T, Taamasri P, Piyaraj P, et al. Drinking water: a possible source of Blastocystis spp. subtype 1 infection in schoolchildren of a rural community in central Thailand. Am J Trop Med Hyg. 2008;79:401-6.

5. Londoño-Franco AL, Loaiza-Herrera J, Lora-Suárez FM, Gómez-Marín JE. Frecuencia y fuentes de Blastocystis sp. en niños de 0 a 5 años de edad atendidos en hogares infantiles públicos de la zona urbana de Calarcá, Colombia. Biomedica. 2014;34:218-27.

6. Guerrant RL, Hughes JM, Lima NL, Crane J. Diarrhea in developed and developing countries: magnitude, special settings, and etiologies. Rev Infect Dis. 1990;12 Suppl $1:$ S41-50.

7. Abdulsalam AM, Ithoi I, Al-Mekhlafi HM, Ahmed A, Surin J, Mak JW. Drinking water is a significant predictor of Blastocystis infection among rural Malaysian primary schoolchildren. Parasitol. 2012;139:1014-20.

8. Mehraj V, Hatcher J, Akhtar S, Rafique G, Beg MA. Prevalence and factors associated with intestinal parasitic infection among children in an urban slum of Karachi. PLOS ONE. 2008;3:e3680. 
Rebolla MF, Silva EM, Gomes JF, Falcão AX, Rebolla MVF, Franco RMB. High prevalence of Blastocystis spp. infection in children and staff members attending public urban schools in São Paulo State, Brazil. Rev Inst Med Trop Sao Paulo. 2016;58:31.

9. Pipatsatitpong D, Rangsin R, Leelayoova S, Naaglor T, Mungthin M. Incidence and risk factors of Blastocystis infection in an orphanage in Bangkok, Thailand. Parasit Vectors. 2012;5:37

10. Instituto Brasileiro de Geografia e Estatística. Diretoria de Pesquisas, Coordenação de População e Indicadores Sociais. São Sebastião da Grama. [cited 2015 Jan 9]. Available from: http://cod.ibge.gov.br/239YT

11. Gomes JF, Hoshino-Shimizu S, Dias LC, Araujo AJ, Castilho VL, Neves FA. Evaluation of a novel Kit (TF-Test) for the diagnosis of intestinal parasitic infections. J Clin Lab Anal. 2004;18:132-8

12. Assis EM, Olivieria RC, Moreira LE, Pena JL, Rodrigues LC, Machado-Coelho GL. Prevalência de parasitos intestinais na comunidade indígena Maxakali, Minas Gerais, Brasil, 2009. Cad Saude Publica. 2013;29:681-90.

13. Carvalho GL, Moreira LE, Pena JL, Marinho CC, Bahia MT, Machado-Coelho GL. A comparative study of the TF-Test ${ }^{\circledR}$, Kato-Katz, Hoffman-Pons-Janer, Willis and Baermann-Moraes coprologic methods for the detection of human parasitosis. Mem Inst Oswaldo Cruz. 2012;107:80-4

14. Carvalho JB, Santos BM, Gomes JF, Suzuki CT, Hoshino-Shimizu S, Falcao AX, et al. TF-Test modified: new diagnostic tool for human enteroparasitosis. J Clin Lab Anal. 2015. [Epub ahead of print]

15. Brasil. Ministério da Saúde. Secretaria de Vigilância em Saúde. Plano nacional de vigilância e controle das enteroparasitoses. Brasília: Ministério da Saúde; 2005.

16. Gorelick MH, Wagner D, McLellan SL. Development and validation of a self-administered questionnaire to measure water exposures in children. Ambul Pediatr. 2008;8:388-91.

17. Nesti MM, Goldbaum M. Infectious diseases and daycare and preschool education. J Pediatr (Rio J). 2007;83:299-312

18. Centers for Disease Control and Prevention. National Center for Emerging and Zoonotic Infectious Diseases. Division of Foodborne, Waterborne, and Environmental Diseases. Cryptosporidium : prevention \& control. [cited 2010 Nov 2]. Available from: http:// www.cdc.gov/parasites/crypto/prevention-control.html

19. Rebolla MF, Franco RM, Silva EM. Proposta para implantar um programa de controle da giardiose em creches: uma necessidade em saúde pública. Prat Hosp. 2010;12:77-82.

20. Queiroz DT, Vall J, Souza AM, Vieira NF. Observação participante na pesquisa qualitative : conceitos e aplicações na área de saúde. R Enferm UERJ. 2007;15:276-83.

21. Cousens S, Kanki B, Toure S, Diallo I, Curtis V. Reactivity and repeatability of hygiene behaviour: structured observations from Burkina Faso. Soc Sci Med. 1996;43:1299308

22. Guimarães S, Sogayar MI. Blastocystis hominis: occurrence in children and staff members of municipal day-care centers from Botucatu, São Paulo state, Brazil. Mem Inst Oswaldo Cruz. 1993:88:427-9.

23. El Fatni C, Olmo F, El Fatni H, Romero D, Rosales MJ. First genotyping of Giardia duodenalis and prevalence of enteroparasites in children from Tetouan (Morocco). Parasite. 2014;21:48.

24. Miller RA, Minshew BH. Blastocystis hominis: an organism in search of a disease. Rev Infect Dis. 1988;10:930-8

25. Stensvold R, Brillowska-Dabrowska A, Nielsen HV, Arendrup MC. Detection of Blastocystis hominis in unpreserved stool specimens by using polymerase chain reaction. J Parasitol. 2006;92:1081-7.

26. Coelho WM, Gomes JF, Amarante AF, Bresciani KD, Lumina G, Hoshino-Shimizu S, et al. A new method for the diagnosis of gastrointestinal parasites in dogs. Rev Bras Parasitol Vet. 2013;22:1-5
27. Gomes JF, Suzuki CTN, Falcao AX, Coelho WMD, Cardia DFF, Inácio SV, et al. Advances in the canine coproparasitological examination. In: Cohen KM, Diaz LR, editors. Dogs: domestication, history, behavior and common health problems. New York: Nova Science; 2013. p. 91-104.

28. Gomes JF, Hoshino-Shimizu S, Falcão AX. Recentes avanços tecnológicos no exame parasitológico de amostras de fezes. Bio Farma. 2008;3:44-53.

29. Roberts T, Ellis J, Harkness J, Marriott D, Stark D. Treatment failure in patients with chronic Blastocystis infection. J Med Microbiol. 2014;63:252-7.

30. David EB, Guimarães S, de Oliveira AP, Goulart de Oliveira-Sequeira TC, Nogueira Bittencourt G, Moraes Nardi AR, et al. Molecular characterization of intestinal protozoa in two poor communities in the State of São Paulo, Brazil. Parasit Vectors. 2015;8:103.

31. Banaticla JE, Rivera WL. Detection the subtype identification of Blastocystis isolates from wastewater samples in the Philippines. J Water Health. 2011;9:128-37.

32. Slifko TR, Smith HV, Rose JB. Emerging parasite zoonoses associated with water and food. Int J Parasitol. 2000;30:1379-93.

33. Mbae CK, Nokes DJ, Mulinge E, Nyambura J, Waruru A, Kariuki S. Intestinal parasitic infections in children presenting with diarrhoea in outpatient and inpatient settings in an informal settlement of Nairobi, Kenya. BMC Infect Dis. 2013;13:243.

34. Strina A. Childhood diarrhea and observed hygiene behavior in Salvador, Brazil. Am J Epidemiol. 2003;157:1032-8.

35. Nagel R, Cuttell L, Stensvold CR, Mills PC, Bielefeldt-Ohmann H, Traub RJ. Blastocystis subtypes in symptomatic and asymptomatic family members and pets and response to therapy. Intern Med J. 2012;42:1187-95.

36. Santos CK, Grama DF, Limongi JE, Costa FC, Couto TR, Soares RM, et al Epidemiological, parasitological and molecular aspects of Giardia duodenalis infection in children attending public daycare centers in southeastern Brazil. Trans R Soc Trop Med Hyg. 2012;106:473-9.

37. Guglielmetti P, Cellesi C, Figura N, Rossolini A. Family outbreak of Blastocystis hominis associated gastroenteritis. Lancet. 1989:2;1394.

38. Mahmud MA, Spigt M, Mulugeta Bezabih A, López Pavon I, Dinant GJ, Blanco Velasco R. Risk factors for intestinal parasitosis, anaemia, and malnutrition among school children in Ethiopia. Pathog Glob Health. 2013;107:58-65.

39. Keystone JS, Krajden S, Warren MR. Person to person transmission of Giardia lamblia in day care whose. Can Med Assoc J. 1978;119:241-8.

40. de Carvalho TB, de Carvalho LR, Mascarini LM. Occurrence of enteroparasites in day care centers in Botucatu (São Paulo State, Brazil) with emphasis on Cryptosporidium sp., Giardia duodenalis and Enterobius vermicularis. Rev Inst Med Trop Sao Paulo. 2006;48:269-73

41. Hoque ME, Hope VT, Scragg R, Kjellström T. Children at risk of giardiasis in Auckland: a case-control analysis. Epidemiol Infect. 2003;131:655-62.

42. King JD, Endeshaw T, Escher E, Alemtaye G, Melaku S, Gelaye W, et al. Intestinal parasite prevalence in an area of Ethiopia after implementing the SAFE strategy, enhanced outreach services, and health extension program. PLOS Negl Trop Dis. 2013;7:e2223

43. Cañete R, Díaz MM, Avalos García R, Laúd Martinez PM, Ponce, FM. Intestinal parasites in children from a day care centre in Matanzas city, Cuba. PLOS One. 2012;7:e51394.

Received: 22 October 2014

Accepted: 06 November 2015 